\title{
SENSORIAMENTO REMOTO, AEROGEOFÍSICA E GEOPROCESSAMENTO APLICADOS AO ESTUDO DE AQÜÍFERO FRATURADO EM TERRENO CRISTALINO, LESTE DO ESTADO DE SÃO PAULO
}

\author{
VANESSA MADRUCCI, CARLOS CÉSAR DE ARAÚJO \& FÁBIO TAIOLI
}

\begin{abstract}
REMOTE SENSING, AIRBORNE GEOPHYSICAL DATA AND GIS TECHINIQUES APLLIED TO FRACTUREDBEDROCK AQUIFER STUDIES, EASTERN SÃO PAULO STATE This work presents the study of a fractured aquifer located in bedrock terrain, in the eastern portion of São Paulo State, Brazil. Remote sensing, airborne geophysical data, GIS techniques and photogeology were applied. Maps of lineaments, morphostructures and joint zones were produced. Analysis of these data was performed with well yield data (specific capacity) using a GIS system. The analysis consists of three steps: photogeologic interpretation with generation of structural lineament map; generation of lineament buffer zones and lineament intersection buffer zones; lineament azimuth analysis and reclassification of maps; cross tabulation between these maps and well yield data was performed. Application of the method serves as an example of the efficiency of remote sensing, airborne geophysics and GIS techniques on fractured aquifer studies. It was possible to define the influence of the structures on the well yield and to delimitate the lineament and lineament intersection influence zones. It was determined for the study area, at a scale of 1:100.000, a high well yield area beyond $200 \mathrm{~m}$ from lineaments and beyond $600 \mathrm{~m}$ from lineament intersections. It was evidenced that high well yields are related to low and intermediary morphostructure features.
\end{abstract}

Keywords: remote sensing, airborne geophysical data, GIS, photointerpretation, geoprocessing, fractured-bedrock aquifer.

\begin{abstract}
Resumo Este trabalho apresenta o estudo de um aqüífero fraturado, em terreno cristalino, na região do leste do Estado de São Paulo, utilizando dados de sensoriamento remoto, aeromagnetométricos, técnicas de processamento de imagens e de fotointerpretação geológica. Foram gerados mapas de lineamentos, morfoestruturas e zonas de juntas. Estes dados foram analisados conjuntamente com dados de produtividade dos poços (capacidade específica), em ambiente SIG, com o auxílio de técnicas de geoprocessamento. A análise consistiu em três etapas: fotointerpretação geológica com a geração dos mapas de lineamentos, morfoestruturas, isofreqüência de zonas de juntas; elaboração do mapa de distâncias dos lineamentos e de suas intersecções, direções de lineamentos e reclassificação dos mapas e tabulação cruzada entre os mapas gerados e a produtividade dos poços. A aplicação do método demonstra a eficiência das técnicas utilizadas no estudo de aqüíferos fraturados. Foi possível definir a influência das feições estruturais na produtividade dos poços, assim como delimitar a área de influência dos lineamentos e de suas intersecções. Determinou-se para a área de estudo, de acordo com a escala de trabalho adotada (1:100.000), uma área de influência na produtividade dos poços de até $200 \mathrm{~m}$ ao redor dos lineamentos e de até 600 $\mathrm{m}$ nas regiões de intersecção de lineamentos. Além disso, constatou-se que as maiores produtividades de poços estão relacionadas às regiões de classes de morfoestruturas baixa e intermediária.
\end{abstract}

Palavras-chave: sensoriamento remoto, dados aerogeofísicos, SIG, fotointerpretação, geoprocessamento, aqüífero cristalino fraturado.

INTRODUÇÃO Atualmente há grande importância da água subterrânea para o abastecimento da população, indústrias e propriedades rurais. Em regiões com predomínio de rochas cristalinas (ígneas ou metamórficas) a infiltração, circulação e acumulação de água se associam a sistemas de fraturas, às morfoestruturas e à intensidade dos sistemas de deformação rúptil.

As rochas cristalinas fraturadas têm grande potencial para a acumulação de água, mas o sucesso em perfurações dos poços depende da avaliação precisa dos condicionantes geológicos dos aqüíferos fraturados. Entre os métodos indiretos de avaliação citam-se o sensoriamento remoto (Waters et al. 1990) e a aerogeofísica, devido à rapidez, acurácia e economia. Ademais, o uso de sistemas de informação geográfica (SIG) permite a sistematização da análise, o que também aumenta a rapidez e acurácia.

A fotointerpretação geológica de imagens auxilia na identificação de feições estruturais relacionadas à prospecção de água subterrânea, tais como lineamentos, fraturas (juntas e falhas) e morfoestruturas. Porém, é necessária a utilização conjunta dos dados de sensoriamento remoto com outros tipos de informação, tais como geofísica, trabalho de campo e dados de poços para uma análise mais confiável.

Nesta análise conjunta são empregadas técnicas de processamento de imagens para gerar produtos integrados digitalmente (Harris et al. 1990, Harris et al. 1994, Dias \& Paradella 1997, Paradella et al. 1998, Madrucci et al. 2002), auxiliares na fotointerpretação geológica, e técnicas de geoprocessamento com o auxílio de SIG (Bonham-Carter 1994), para a análise dos dados.

Alguns trabalhos relacionam as estruturas dos maciços rochosos, interpretadas como lineamentos em imagens de satélite, e dados de poços tubulares, pela análise da posição dos mesmos e sua produtividade em relação aos lineamentos (Sampaio 1987, Rocio \& Veneziani 1993, Gustafson 1994, Mabee et al. 1994, Sander et al. 1996, Sander 1997, Fernandes \& Rudolph 2001).

Este trabalho discute a aplicação da fotointerpretação de imagens satélite na elaboração de mapa morfoestrutural e de isofreqüência de zonas de juntas e principalmente do produto 

do Estado de São Paulo

integrado Landsat Enhanced Thematic Mapper Plus (ETM+) e aeromagnetometria na elaboração do mapa de lineamentos.

Também são apresentadas análises espaciais, por geoprocessamento, de produtividade dos poços tubulares cadastrados e sua relação quantitativa com lineamentos, morfoestruturas e densidade de zonas de juntas. Este trabalho contribui na definição de parâmetros que auxiliam na elaboração de modelo hidrogeológico conceitual e fornece dados para futuras análises de favorabilidade.

LOCALIZAÇÃO E GEOLOGIA DA ÁREA A área de estudo localiza-se na região do Circuito das Águas (cidades de Amparo, Serra Negra, Lindóia, Águas de Lindóia, Socorro, Itapira), porção leste do Estado de São Paulo, e abrange cerca de $2000 \mathrm{~km}^{2}$. A região possui diversas empresas engarrafadoras de água mineral, procedente de fontes naturais e poços artesianos. Consiste de rochas do embasamento cristalino do Paleo e Neoproterozóico. A região teve evolução policíclica que modificou as rochas originais por metamorfismo, cisalhamento, migmatização e intrusões.

Segundo Campos Neto et al. (1990), a área se insere na Faixa Alto Rio Grande, (Amparo, Serra Negra) e na Nappe SocorroGuaxupé (Socorro). Segundo Artur (1988), nesta região ocorrem as Faixas de Cisalhamento Pouso Alegre e Ouro Fino, ambas com direção NE-SW e caráter transpressivo dextral. A Faixa de Cisalhamento Pouso Alegre é caracterizada pelo predomínio de imbricações, envolvendo seqüências de coberturas e porções de infra-estrutura devido a falhas de empurrão. Possui foliação feqüentemente subhorizontal, localmente empinada por redobramento e pela superposição de falhas transcorrentes (Artur 1988). A Faixa de Cisalhamento Ouro Fino é uma faixa rúptil, transcorrentes, com componentes verticais e de empurrão. Não exibe sinais de redobramento regional e intercepta rochas da Faixa de Cisalhamento Pouso Alegre, o que denota seu caráter mais jovem, mesmo com certa superposição temporal entre seus desenvolvimentos. Consiste de protomilonitos, cataclasitos e milonitos, que denotam deformações predominantemente rúpteis e rúpteisdúcteis (Artur 1988).

Também ocorrem rochas paleoproterozóicas, pertencentes ao Complexo Amparo, representadas por gnaisses migmatíticos e ortognaisses tonalíticos a granodioríticos pertencentes ao Complexo Itapira, além de paragnaisses, quartzitos, granitóides e anfibolitos. As rochas neoproterozóicas são representadas pelo Complexo Pinhal, composto de migmatito granítico, gnaisse e intercalação de rochas metassedimentares, intrusões graníticas, granodioríticas e charnoquíticas com intercalações de xistos e gnaisses. A estruturação é marcante na direção NE-SW, com a presença de anticlinais e sinclinais (Fig. 1).

ASPECTOS HIDROGEOLÓGICOS Naárea ocorre um sistema aqüífero cristalino, em rochas pré-cambrianas. $\mathrm{O}$ aqüífero ocorre em descontinuidades provocadas por fraturamento (porosidade de fissuras), caracterizando zonas aqüíferas localizadas, com extensão e profundidade condicionadas pela intensidade do fraturamento.

O manto de intemperismo das rochas apresenta grande importância na recarga do aqüífero e conseqüentemente no escoamento da rede de drenagem . Dependendo do tipo litológico, altitude, clima e fraturamento, o manto de intemperismo na área pode apresentar espessuras entre 10 e $70 \mathrm{~m}$. Segundo DAEE (1981), neste aqüífero as zonas produtoras situam-se a profundidade de até 165 $\mathrm{m}$ (Tabela 1 e Fig. 2). A figura 3 apresenta um esquema simplificado de circulação de água no sistema aqüífero cristalino.
O clima da área é subtropical muito úmido, praticamente sem estiagem, com pluviosidade superior a $1300 \mathrm{~mm}$, crescente nas direções das cristas das serras, e evapotranspiração anual menor que $1000 \mathrm{~mm}$ baixando na direção das serras. O relevo é acidentado, com elevação entre 640 a 1280 m.

MATERIAIS E MÉTODOS Empregou-se os seguintes materiais: a) imagem Landsat 7 - ETM+ (bandas 1, 2, 3, 4, 5, 6, 7 e pancromática), órbita/ponto 219/076, aadquirida em 03 de setembro de 1999, resolução espacial de $30 \mathrm{~m}$ (bandas 1 a 7) e de 15 metros (pancromática), em formato digital; b) rede de drenagem da área digitalizada, referente às cartas topográficas IBGE: Munhoz, Socorro, Amparo, Águas de Lindóia, Mogi Guaçu, todas em escala 1:50.000; posteriormente a rede de drenagem foi complementada com a imagem pancromática do sensor ETM+; c) dados aeromagnetométricos do Projeto São Paulo-Rio de Janeiro (CPRM) de 1979, com direção das linhas de vôo N-S, espaçamento entre as linhas de vôo 1 km e altura do vôo 150 m (CPRM, 1995); d) dados de poços tubulares fornecidos pela CPRM e DAEE e também obtidos em etapas de campo, num total de 63 poços.

O método utilizado consistiu de quatro etapas: a) pré-processamento e processamento das imagens ETM+ e aeromagnetométrica; b) construção de banco de dados em SIG; c) fotointerpretação geológica do produto integrado ETM+-aeromagnetométrica e geração de mapas de lineamentos e morfoestrutural; d) análise por geoprocessamento dos dados de poços e de lineamentos, morfoestruturas e freqüência de zonas de juntas (Fig. 4).

Pré-processamento A imagem ETM+ foi submetida à correção atmosférica pelo método de "subtração do pixel escuro" (Chavez Jr 1975) e geométrica. O pré-processamento dos dados aerogeofísicos consistiu na conversão dos dados originais em grades regulares (250 m), micronivelamento (Minty 1991) e geração das imagens magnetométricas campo total e fase do sinal analítico.

A interpolação bidirecional foi realizada em função da distribuição dos dados originais e do procedimento de micronivelamento adotado. O método bidirecional é indicado para interpolar rapidamente linhas de dados aproximadamente paralelas, pois tende a intensificar trends perpendiculares às direções das linhas do levantamento (Geosoft 1995). Em dados aerogeofísicos os melhores resultados são alcançados quando a interpolação é feita por curvatura mínima, krigagem e bidirecional (Parro 1998).

O micronivelamento é utilizado para remover erros residuais de nivelamento de dados aerogeofísicos, por filtragem direcional. Segundo Geosoft (2001), o micronivelamento pode ser definido como a filtragem de um conjunto de dados (em forma de grade) para reduzir ou remover efeitos não geológicos causados por ruídos de alto comprimento de onda, ao longo das linhas do aerolevantamento. Neste trabalho empregou-se o micronivelamento por interpolação bi-direcional de linhas (Geosoft 2001).

Segundo Fuck (2000), o sinal analítico realça estruturas e descontinuidades com expressão magnética, sendo útil no mapeamento de estruturas geológicas. O sinal analítico é uma função complexa e a sua fase corresponde ao ângulo entre a parte real e a imaginária em cada ponto da função, isto é, entre a derivada vertical e o gradiente do campo magnético. A fase do sinal analítico não produz grande número de estruturas nas imagens de derivadas, que nem sempre correspondem a feições estruturais reais e define melhor os diversos domínios magnéticos (Fig. 5).

Processamento Na imagem ETM+ foi realizada a transformação 


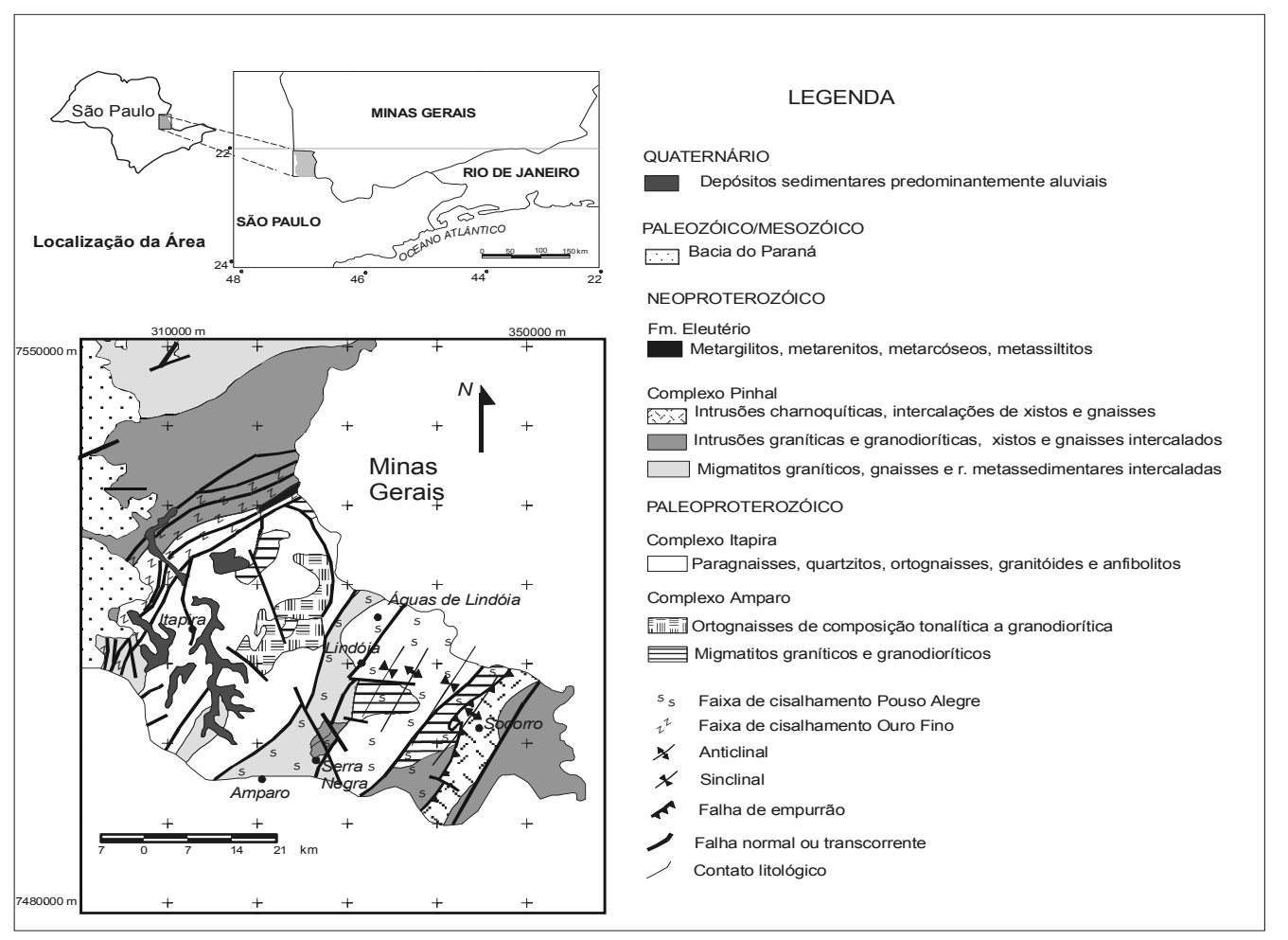

Figura 1 - Localização e geologia da área.

Tabela 1 - Potencial hídrico subterrâneo com base em dados de poços.

\begin{tabular}{|c|c|c|c|c|c|c|}
\hline \multirow{2}{*}{$\begin{array}{c}\mathrm{N}^{0} \text { de } \\
\text { poços } \\
\text { estudados }\end{array}$} & \multirow{2}{*}{$\begin{array}{c}\text { Profundidade } \\
\text { média dos } \\
\text { poços }(\mathrm{m})\end{array}$} & \multicolumn{4}{|c|}{$\begin{array}{c}\text { Capacidade Específica } \\
\left(\mathrm{m}^{3} / \mathrm{h} / \mathrm{m}\right)\end{array}$} \\
\cline { 3 - 7 } & $\begin{array}{c}\text { Média } \\
\text { aritm. }\end{array}$ & Mediana & $\begin{array}{c}\text { Valor } \\
\text { máx. }\end{array}$ & $\begin{array}{c}\text { Valor } \\
\text { mín. }\end{array}$ & $\begin{array}{c}\text { Desvio } \\
\text { Padrão }\end{array}$ \\
\hline 63 & 120 & 0,83 & 0,18 & 11,40 & 0,01 & 1,87 \\
\hline
\end{tabular}

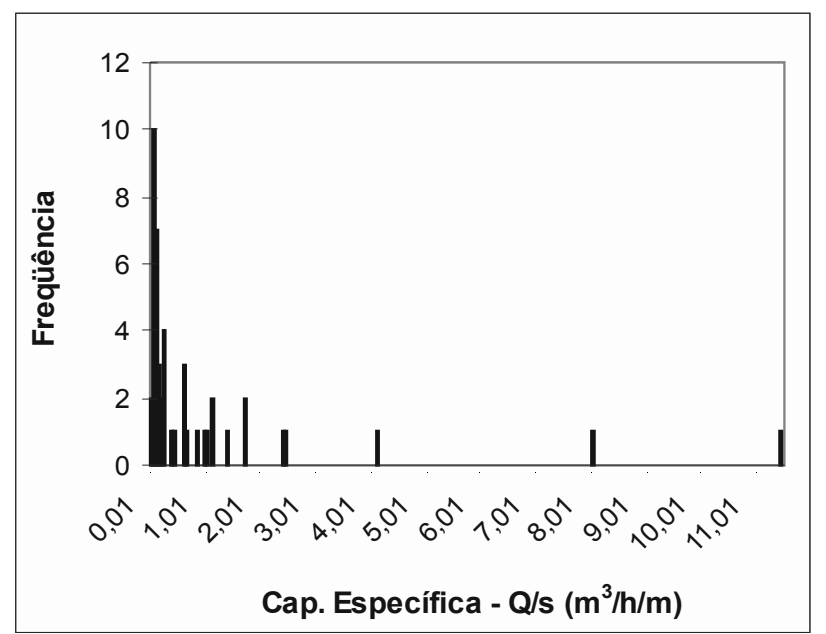

Figura 2 - Histograma da capacidade especifica dos poços na área. Fonte dos dados: CPRM (SIAGAS), DAEE e dados obtidos pelos autores em etapa de campo.

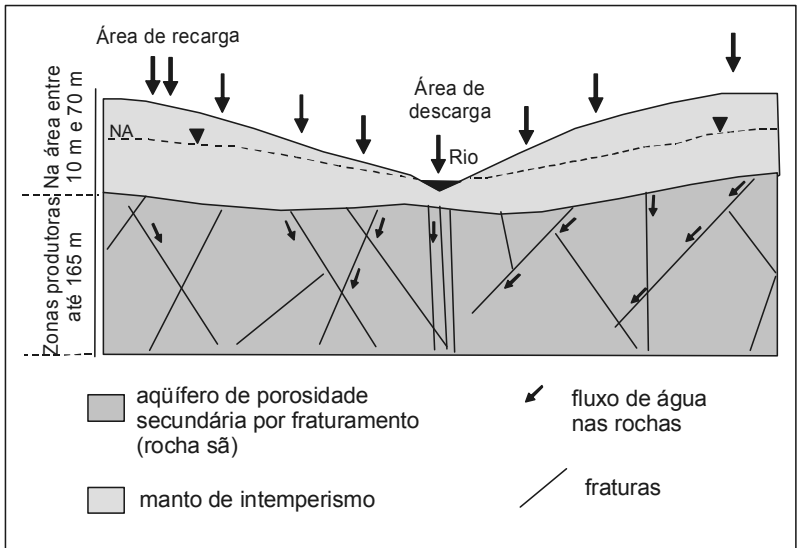

Figura 3 - Modelo hidrogeológico de aqüifero cristalino. Adaptada de Hirata e Ferreira (2001).

por componentes principais (bandas 1, 2, 3, 4, 5, 6 e 7). Utilizou-se o primeiro componente (1CP), pois realça as feições de relevo e drenagem da imagem. Escolheu-se a técnica IHS para a integração de dados ETM+ e magnetometria. Esta é a mais flexível e apresenta o melhor desempenho na combinação e integração de dados geológicos multifontes (Harris et al. 1994).

Na etapa de correção de imagens coletou-se 19 pontos de controle. Como o valor de erro médio na correção geométrica da imagem ETM+ foi de $30 \mathrm{~m}$ e esta imagem possui resolução espacial de $30 \mathrm{~m}$, este valor foi escolhido como tamanho de pixel comum às imagens (Harris et al. 1990, Rolim 1993, Harris et al. 1994, Dias \& Paradella 1997, Santos 1999, Madrucci 2000). 
Sensoriamento remoto, aerogeofísica e geoprocessamento aplicado ao estudo de aquífero fraturado em terreno cristalino, leste do Estado de São Paulo

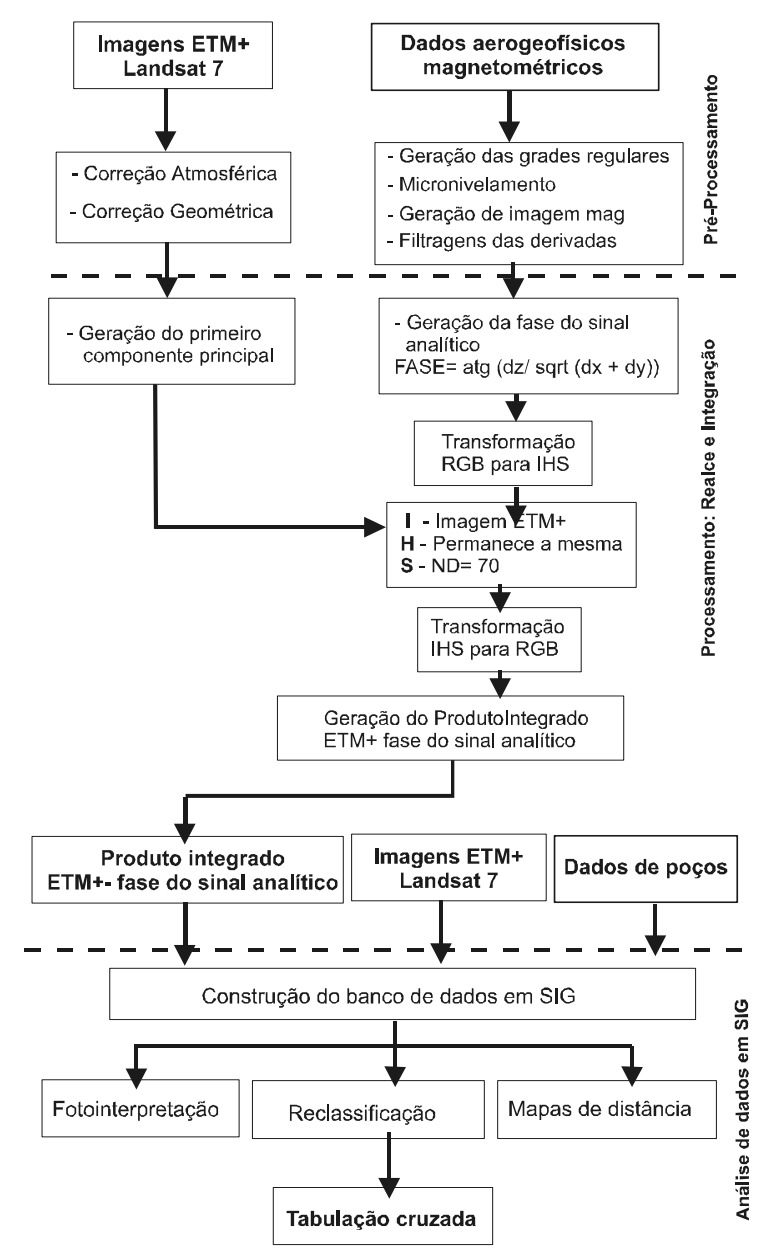

Figura 4 - Fluxograma do método utilizado.

A integração da imagem ETM+ e magnetometria foi feita da seguinte maneira:

a) Importação da imagem magnetométrica (fase do sinal analítico) e conversão para o espaço RGB;

b) Transformação RGB para IHS, utilizando-se os canais obtidos no item a;

c) Substituição dos canais Intensidade (I) pela imagem Landsat 7 - ETM+ $\left(1^{\circ}\right.$ componente principal - CP) realçada linearmente, Saturação $(S)$ por um valor constante (nível de cinza=70) e manutenção do canal de Matiz $(\mathrm{H})$ original;

d) Retorno ao espaço RGB, pela aplicação da transformação inversa IHS para RGB.

Segundo Lowman et al. (1987) e Harris (1991), nas imagens de satélite há atenuação das feições topográficas localizadas na direção de iluminação do sensor, com variação de $\pm 20^{\circ}$. Como a imagem ETM+ foi adquirida sob condições de iluminação com fonte solar de azimute $50^{\circ}$, as feições estruturais que apresentam direção aproximadamente $\mathrm{N} 50 \mathrm{E}\left( \pm 20^{\circ}\right)$ são atenuadas ou não identificadas. Além disso, como a imagem ETM+ é recente, muitas vezes a interpretação de lineamentos pode ser prejudicada devido ao uso e ocupação do solo. Para solucionar este problema podese utilizar imagens integradas com azimute de iluminação solar (sensores ópticos) ou azimute de imageamento (radar) diferentes, tais como TM-Radarsat ou Radarsat ascendente e descente para interpretação dos lineamentos, como realizado por Madrucci (2000),

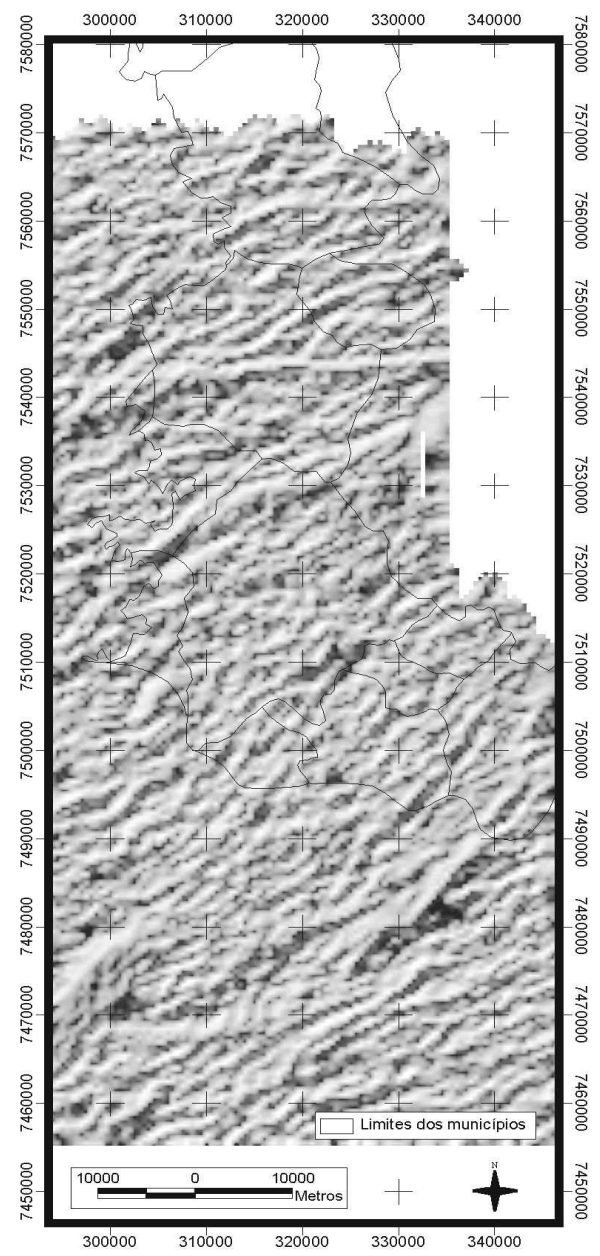

Figura 5 - Imagem aeromagnetométrica fase do sinal analítico

porém o custo é elevado. Uma maneira de solucionar este problema é a integração digital da imagem óptica com dados aeromagnetométricos (fase do sinal analítico).

A imagem ETM+é o produto base para a integração, pois apresenta feições texturais de relevo e drenagem não registradas em imagens aerogeofísicas. O emprego do produto integrado ETM+ e fase do sinal analítico possibilita a análise conjunta desses dados, isto é, apresenta informações estruturais fornecidas pela fase do sinal analítico (representadas pelos matizes) e as informações texturais de relevo e drenagem fornecidas pela imagem ETM+.

As imagens processadas foram inseridas num banco de dados espacial de modo a se realizar a fotointerpretação dos lineamentos. Posteriormente, o mapa morfoestrutural e os dados de poços e fontes cadastrados também foram inseridos neste banco para realizar as análises espaciais entre os lineamentos, morfoestruturas, isofreqüência de zonas de juntas e os dados de poços.

O parâmetro hidrogeológico utilizado para a análise foi produtividade dos poços tubulares, representada pelos valores de capacidade específica $\mathrm{em} \mathrm{m}^{3} / \mathrm{h} / \mathrm{m}$.

Fotointerpretação Na etapa de fotointerpretação das imagens utilizou-se a sistemática desenvolvida por Riverau (1972) e Soares \& Fiori (1976), adaptado para imagens de satélite por Veneziani e Anjos (1982). O método consiste no reconhecimento de elementos texturais e de interesse; fotoanálise: reconhecimento das leis e 
da complexidade de organização dos elementos texturais de interesse; e na fotointerpretação: estabelecimento da correspondência entre a imagem fotográfica e o modelo do fenômeno registrado no terreno. Esta etapa foi realizada em ambiente SIG.

LINEAMENTOS Neste trabalho adota-se a definição de lineamento definido por O'Leary et al. (1976), como uma feição linear mapeável, simples ou composta, contínua ou descontínua, da superfície terrestre, cujas partes estão alinhadas em arranjo retilíneo ou suavemente curvo e que difere distintamente dos padrões de feições adjacentes, refletindo um fenômeno de subsuperfície.

Os lineamentos foram obtidos a partir de interpretação em tela. Utilizou-se como base para a interpretação o produto integrado $1^{0}$ CP ETM+ e fase do sinal analítico (Figs. 6 e 7). Realizou-se a interpretação observando-se as feições lineares de drenagem (preferencialmente) e de relevo fornecidas pela imagem ETM + e pela resposta magnetométrica (valores altos $=$ magenta) que indicam estruturas e descontinuidades com alguma expressão magnética.

Além deste produto, utilizou-se também a rede de drenagem da área em formato digital. Esta foi complementada pela digitalização dos vetores da rede de drenagem sobrepostos na imagem ETM+ (banda pancromática) e auxiliou na fotointerpretação dos lineamentos. Também utilizou-se a rede de drenagem digitalizada (complementada) para comparação com feições de drenagem interpretadas no produto integrado. Certos elementos lineares interpretados no produto integrado ETM+-fase do sinal analítico, algumas vezes não aparecem na rede de drenagem digitalizada, principalmente em função da resposta da magnetometria.

MAPA MORFOESTRUTURAL O mapa morfoestrutural foi elaborado a partir dos mapas de drenagem e de lineamentos. Baseou-se na análise das simetrias-assimetrias da drenagem e da tropia, que permitem o traçado de curvas não cotadas, que indicam o comportamento das grandes flexuras regionais. Os princípios da análise morfoestrutural foram desenvolvidos para a geologia do petróleo em bacias sedimentares e descritos por Riverau (1972), Mattos et al. (1982) e Soares et al. (1982). Vários autores (Veneziani 1987, Sampaio 1987, Oliveira 1997, Madrucci et al. 2002) elaboraram mapas morfoestruturais para regiões cristalinas.

A elaboração do mapa morfoestrutural em regiões cristalinas se baseia em duas premissas: o predomínio de esforços distensivos no Mesozóico e Terciário e a reativação das antigas linhas de fraqueza crustal. Esforços compressivos significativos, capazes de gerar deformações dúcteis, encerraram, de modo geral, ao final do Neoproterozóico no território brasileiro. A partir daí dominam esforços distensivos. Um pico de distensão generalizada ocorreu no Mesozóico, representado por derrames de lavas e intrusões. Outro pico ocorreu no Terciário, com a formação de bacias, como as de São Paulo e Taubaté. Esta tectônica distensiva reativou antigas linhas de fraqueza crustal, que, até o final do Pré-Cambriano exerciam controles deformacionais compressivos. O movimento dos blocos por gravidade nas regiões cristalinas envolveu todo o pacote litoestrutural pré-existente, soerguendo-o em determina dos locais e rebaixando-o em outros, isto é, gerando flexuras do dimensões quilométricas até a escala de afloramentos. Os baixos altos estruturais resultantes dessas flexuras refletem-se na rede d drenagem atual.

Assim, analisando a simetria-assimetria e a tropia da rede do drenagem, bem como os limites dos blocos definidos pelas anti gas linhas de fraqueza crustal, é possível delinear curvas não co tadas que representam as flexuras (altos e baixos estruturais). importante ressaltar, como nas demais áreas temáticas de mapeamento, que o detalhe morfoestrutural depende da escala de trabalho. No caso, é compatível com a escala 1:100.000, isto é, o mapa representa feições morfoestruturais regionais.

Na elaboração deste mapa também foram utilizados os lineamentos que ocorrem na área e que teriam influência na definição dos desenhos das anomalias morfoestruturais, seja truncando ou deslocando a anomalia, fechando ou limitando a área da anomalia ou mesmo invertendo o mergulho regional ou local.

O mapa foi, então, digitalizado e atribuídos valores para as linhas não cotadas, de modo a gerar uma imagem em tons de cinza, com os respectivos valores. A figura 8 contem o mapa morfoestrutural da área com a maior concentração de poços, e também a imagem do mapa morfoestrutural em 3D, para a melhor identificação dos altos e baixos morfoestruturais.

MAPADE ISOFREQÜÊNCIADEZONASDEJUNTAS Adotouse o conceito de zonas de juntas (Plicka 1974), que contempla sistemas de fraturas paralelas a subparalelas, com espaçamento bem definido (centimétrico a métrico), estendem-se até centenas de quilômetros e podem atingir grandes profundidades.

Elaborou-se o mapa de densidade de zonas de juntas a partir do mapa da rede de drenagem (escala 1:50.000) complementado com as imagens ETM+ e extraindo as feições lineares retilíneas de drenagem e adotando um valor de $0,25 \mathrm{~cm}$, que corresponde a 250 m no terreno (escala 1:100.000).

Adotou-se as feições lineares retilíneas de drenagem porque os sistemas de fraturas verticais que se estendem por até centenas de $\mathrm{km}$ representam linhas de fraqueza crustal, reativadas por processos distensivos. Já as feições ligeiramente a medianamente curvilíneas representam a intersecção de planos de fraturas com médios a baixos mergulhos, por efeito erosivo, e normalmente resultam de deformação localizada, como dobras flexurais. Neste caso, comprometem a definição das antigas linhas de fraqueza reativadas.

Realizou-se a contagem destas feições (por unidade de área) e sua interpolação pelo método do inverso do quadrado da distância. A distribuição homogênea dos dados e a necessidade de observar a distribuição de densidade das feições conduziram à escolha do inverso do quadrado da distância como método de interpolação. O processamento foi digital e o resultado é o mapa de isofreqüência de zonas de juntas, com 12 classes (Fig. 9).

Sistema de informação geográfica (SIG) A utilização destas técnicas se justifica pela facilidade de entrada e recuperação de dados no sistema e inúmeros métodos de análise por geoprocessamento. Segundo Bonham-Carter (1994) a análise em SIG, além de conduzida visualmente, também o pode ser por medidas, cálculos estatísticos e regressão. A integração de dados pode ser feita com base em ponderações por peritos (Araújo \& Macedo 2002) ou por pesos obtidos a partir da análise dos dados espaciais (Rostirolla 1997). Este artigo contribui na etapa de análise dos dados.

As imagens processadas e inseridas no banco de dados espacial permitiram a fotointerpretação dos lineamentos e determinar a isofreqüência das zonas de juntas. Posteriormente, o mapa morfoestrutural e os dados de poços cadastrados também foram inseridos no banco de dados para a análise espacial entre os lineamentos, morfoestruturas, isofreqüência de zonas de juntas e os dados de produtividade dos poços.

ANÁLISE DOS DADOS A análise (tabulação cruzada) entre a produtividade de poços e sua proximidade com os lineamentos 

do Estado de São Paulo

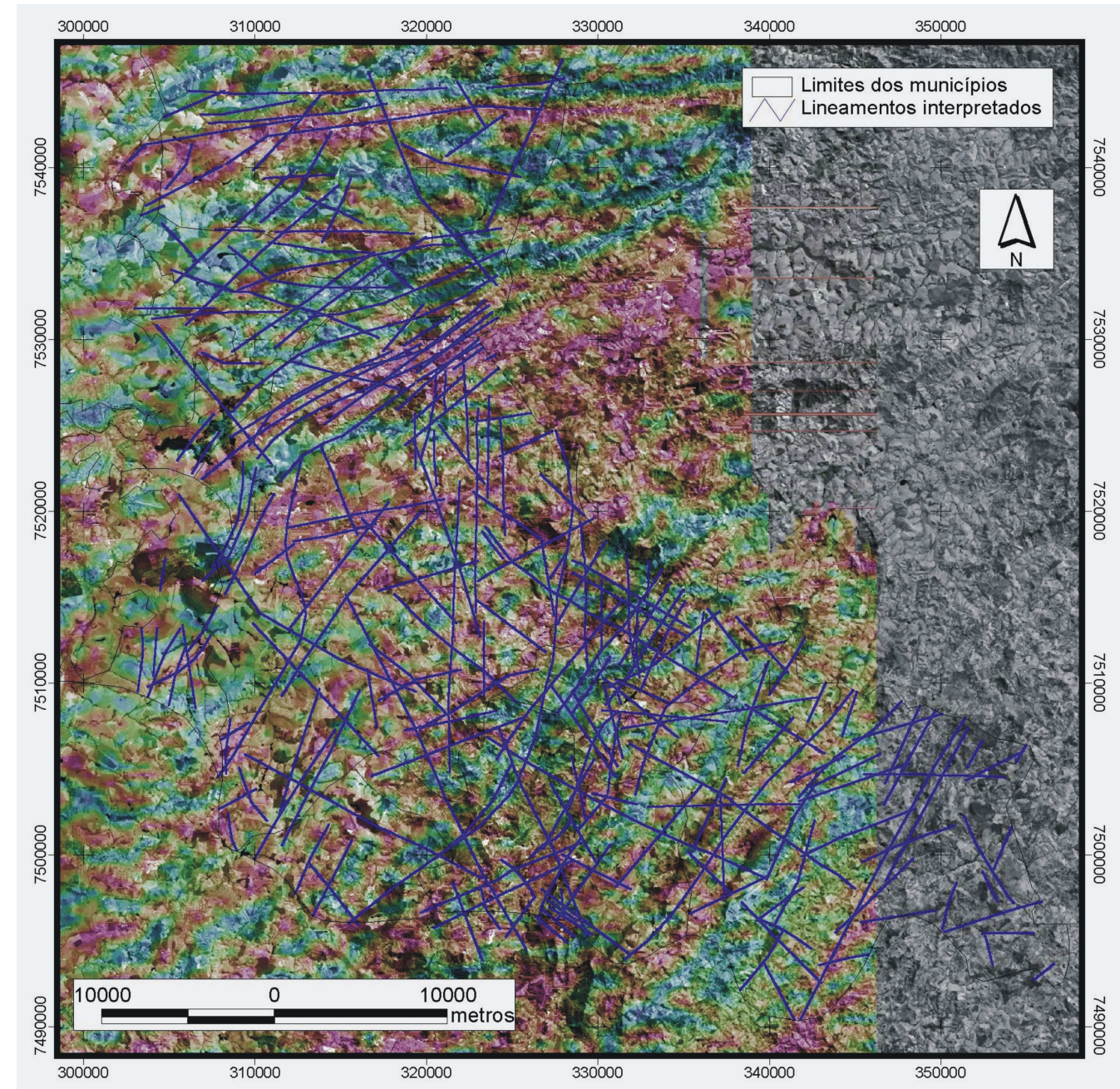

Figura 6-Produto integrado (pelo método IHS) ETM+ Landsat 7 (1CP) e fase do sinal analítico, com os lineamentos interpretados. A textura é fornecida pela imagem ETM+e as cores (RGB) pela magnetometria fase do sinal analítico.

permitiu comparar as categorias entre duas imagens da mesma localização. Esta operação pode ser descrita como a sobreposição de duas matrizes (imagens) com operação lógica $\mathrm{E}(A N D)$. O resultado é expresso em forma gráfica, onde a abcissa representa distâncias e a ordenada a produtividade dos poços. Também avaliouse a influência da intersecção e direção dos lineamentos, da presença de morfoestruturas positivas e negativas e da densidade de zonas de juntas na produtividade dos poços.

Produtividade $\mathbf{x}$ distância de lineamentos A análise entre a produtividade dos poços e a distância dos lineamentos realizouse em duas etapas. Primeiro elaborou-se um mapa de distância entre lineamentos, definidos em classes de 100 m, estabelecendose corredores (buffer) em torno dos mesmos. Posteriormente, fezse a tabulação cruzada entre o mapa de distâncias e a produtividade dos poços (Fig. 10). Conforme se observa, os maiores valores de produtividade $\left(>0,8 \mathrm{~m}^{3} / \mathrm{h} / \mathrm{m}\right)$ se relacionam a poços mais próximos dos lineamentos, entre 100 e $200 \mathrm{~m}$. Isso significa que a área de influência dos lineamentos na produtividade de poços é de até $200 \mathrm{~m}$, considerando-se lineamentos interpretados em escala de trabalho 1:100.000. A figura 11 apresenta a freqüência acumulada da capacidade específica de poços locados à distâncias de até 200 m e acima de $200 \mathrm{~m}$, em relação aos lineamentos. O gráfico mostra que, na área estudada, a influência dos lineamentos na produtividade é de até $200 \mathrm{~m}$. Produtividade superior a $1 \mathrm{~m}^{3} / \mathrm{h} / \mathrm{m}$ corresponde a um valor superior a média dos poços perfurados na área.

Produtividade $x$ intersecção de lineamentos A análise da produtividade dos poços em relação à distância da intersecção dos lineamentos foi feita em duas etapas. Primeiro foram digitalizados os pontos de intersecção entre lineamentos, seguido da elaboração de um mapa de distâncias dos pontos de intersecção, com classes de $50 \mathrm{~m}$. Em seguida realizou-se a tabulação cruzada entre os dados (Figs. 12 e 13).

Conforme se observa, os maiores valores de capacidade específica $\left(>0,8 \mathrm{~m}^{3} / \mathrm{h} / \mathrm{m}\right.$, produtividade média da área) relacionam-se às distâncias entre as intersecções de lineamentos de 100, 150, 300 e $600 \mathrm{~m}$. Baixas produtividades relacionam-se, em geral, com distâncias maiores $(950,1250 \mathrm{e} 1500 \mathrm{~m})$.

Dessa forma, no caso das intersecções dos lineamentos, as distâncias de influência na produtividade de poços são sensivelmente maiores em relação aos lineamentos isolados.

Produtividade x direção de lineamentos O resultado da tabulação cruzada entre produtividade dos poços e direções dos lineamentos é apresentado na figura 14 . Os maiores valores de produtivida- 


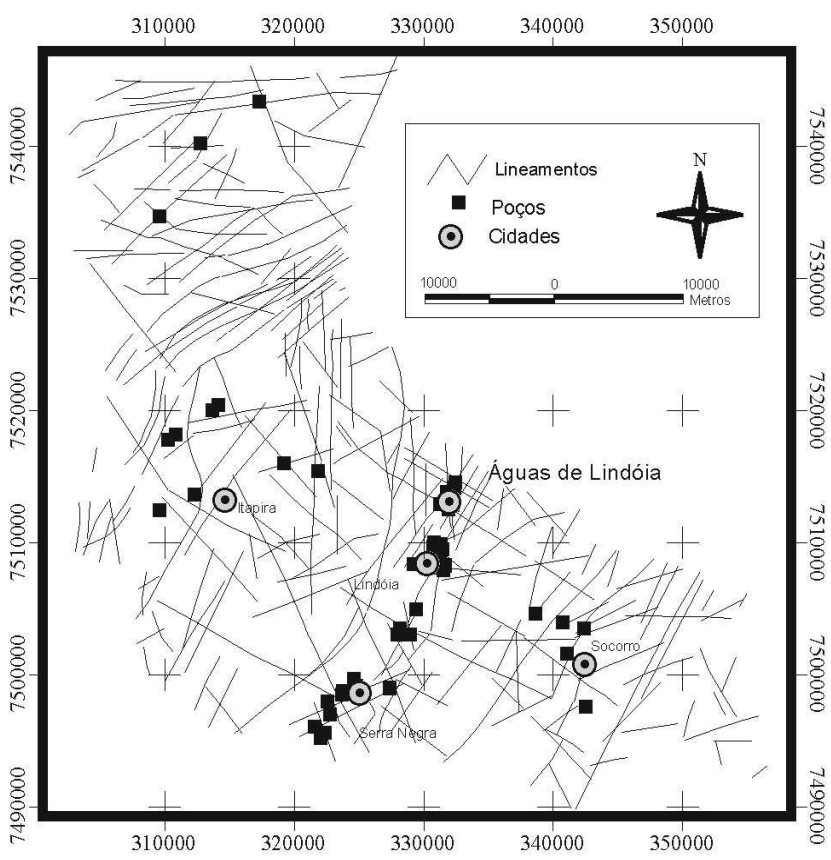

Figura 7 - Mapa de lineamentos e localização dos poços

$\operatorname{des}\left(>8 \mathrm{~m}^{3} / \mathrm{h} / \mathrm{m}\right)$ relacionam-se às direções N-S, NE-SW e NW-SE. A direção E-W apresenta os menores valores de produtividade $(<$ $5 \mathrm{~m}^{3} / \mathrm{h} / \mathrm{m}$ ). Porém, os lineamentos com direção E-W não possuem poços com produtividade muito próxima de zero, como é o caso das outras direções. Isso significa que esses lineamentos possuem maior possibilidade de conter poços produtivos.

Nota-se também que, mesmo nas direções de lineamentos com poços com as maiores capacidades específicas também se encontram poços com baixas produtividades. Isso significa que a produtividade dos poços não é condicionada somente à determinada direção de lineamentos, mas também a outros fatores, como grau de abertura de fraturas e feições morfoestruturais.

Produtividade x mapa morfoestrutural A tabulação cruzada entre dados de produtividade de poços e sua localização em relação ao mapa morfoestrutural foi realizada para toda a área (Fig. 15). As classes de morfoestruturas são baixa, intermediária e alta (Fig. 8). Pelo gráfico nota-se que os poços mais produtivos se localizam em baixos morfoestruturais e intermediários.

Produtividade $x$ mapa de isofreqüência de zonas de juntas $\mathrm{O}$ mapa de isofreqüência de zonas de juntas apresenta 12 classes. Porém, nenhum poço está locado nas regiões classificadas como maior densidade (valores de contagem de 9 a 12). Para avaliar a influência da densidade de fraturas e a produtividade dos poços, após a tabulação cruzada, gerou-se um gráfico (Fig. 16) de freqüência acumulada da capacidade específica dos poços agrupados de acordo com sua localização nas classes de isofreqüência de zonas de juntas (classes 1 a 2, menos densas, 3 a 4, 5 a 6 e 7 a 8 , classes mais densas e que possuem poços).

Conforme se observa, não há relação direta entre densidade de zonas de juntas e produtividade de poços. A classe com menor quantidade de zonas de juntas ( 1 a 2) apresenta capacidade específica inferior e superior ao valor médio da área $\left(0,8 \mathrm{~m}^{3} / \mathrm{h} / \mathrm{m}\right)$. Já a classe com maior quantidade de zonas de juntas ( 7 a 8 ) possui capacidade específica menor.
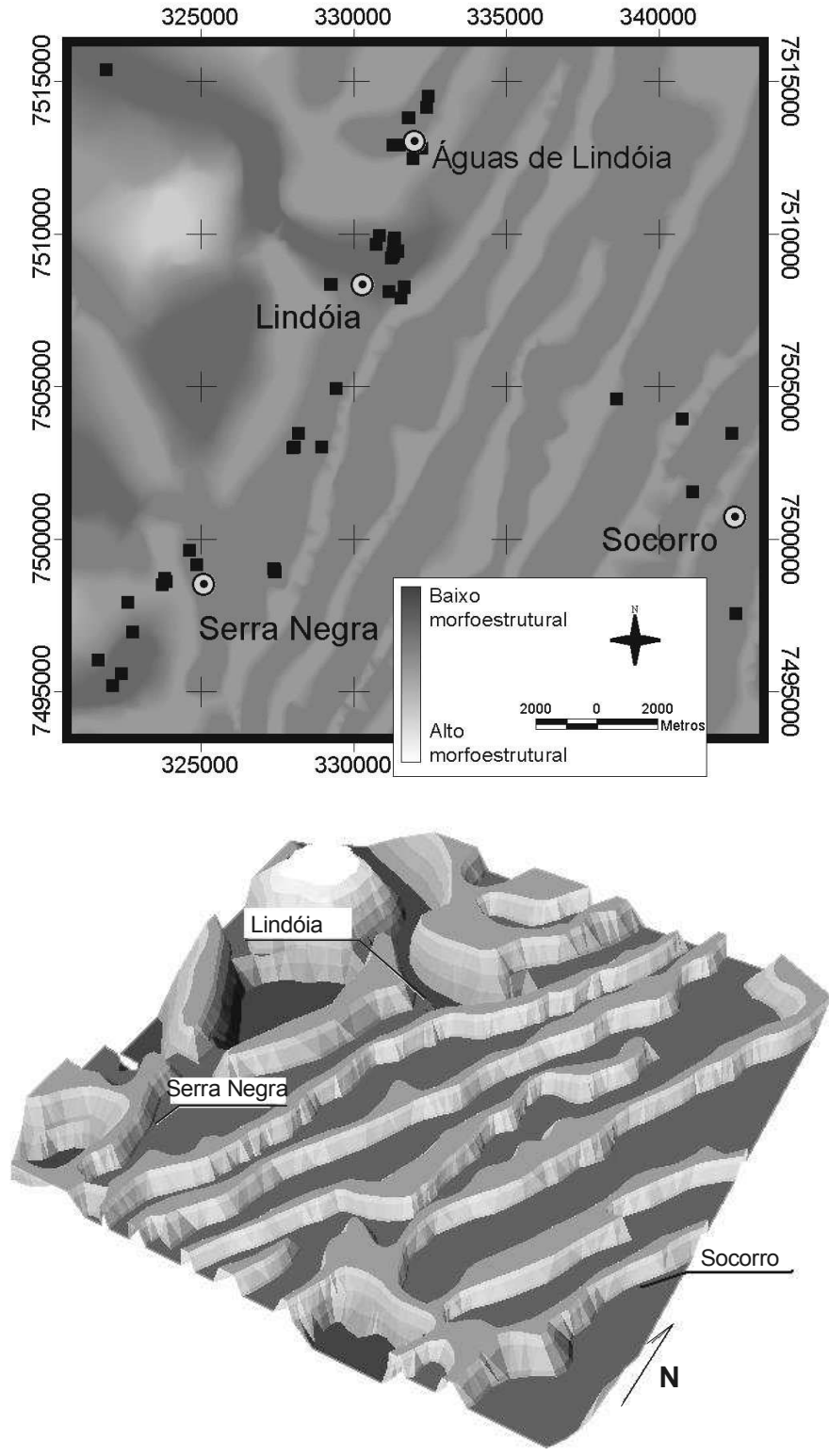

Figura 8 - Mapa morfoestrutural e localização dos poços.

CONCLUSÕES E RECOMENDAÇÕES Oemprego de imagens de sensoriamento remoto integradas com dados aeromagnetométricos (fase do sinal analítico) auxilia a interpretação de lineamentos, destaaca lineamentos atenuados devido ao azimute de iluminação solar da imagem ETM+e diminui custos. As técnicas de geoprocessamento na comparação entre valores de produtividade de poços (= capacidade específica) e outros parâmetros (distância de lineamentos, distância de sua intersecção, direção dos lineamentos, morfoestruturas e classes de densidade de zonas de juntas) contribui para a qualidade científica do trabalho, devido à sistematização da análise, e aumenta a rapidez e acurácia.

Os resultados das análises por geoprocessamento entre lineamentos e produtividade dos poços confirmam a influência da presença destes na produtividade. Além disso, determinou-se que, na área de estudo e escala de trabalho (1:100.000), a distância da influência dos lineamentos é de $200 \mathrm{~m}$. Isso significa que os poços 
Sensoriamento remoto, aerogeofísica e geoprocessamento aplicado ao estudo de aquífero fraturado em terreno cristalino, leste do Estado de São Paulo

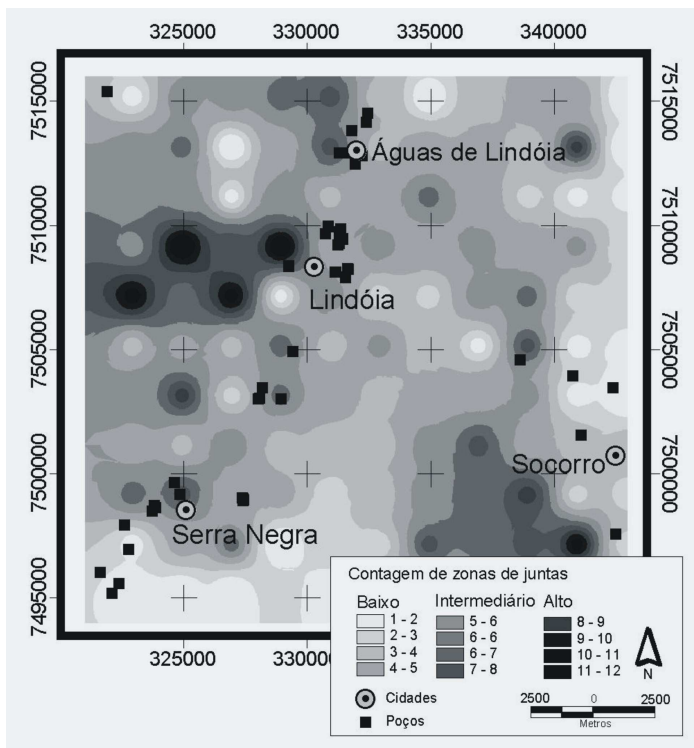

Figura 9 - Mapa de isofreqüência de zonas de juntas e localização dos poços

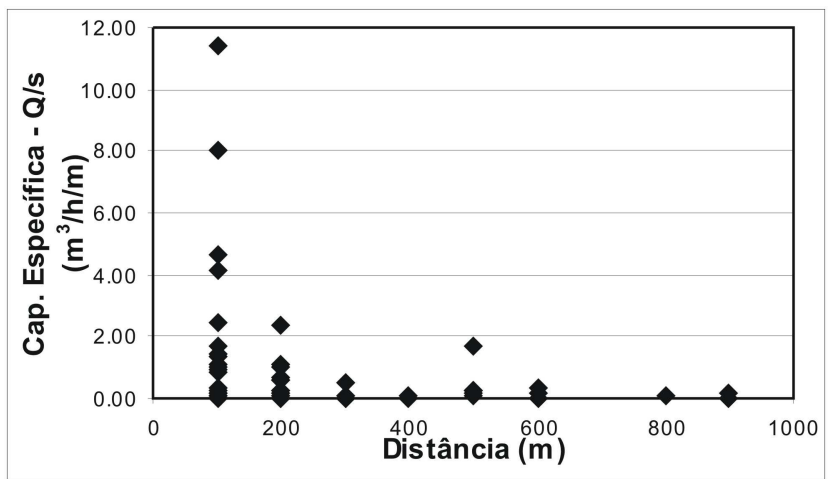

Figura 10 - Distância de lineamentos X capacidade específica.

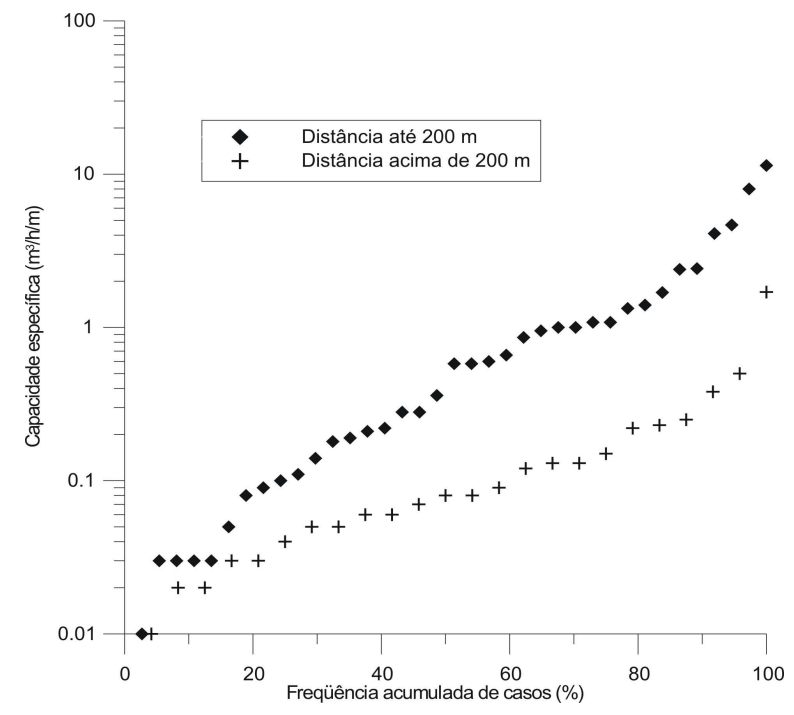

Figura 11 - Freqüencia acumulada da capacidade especifica dos poços agrupados em função de sua distância em relação aos lineamentos.

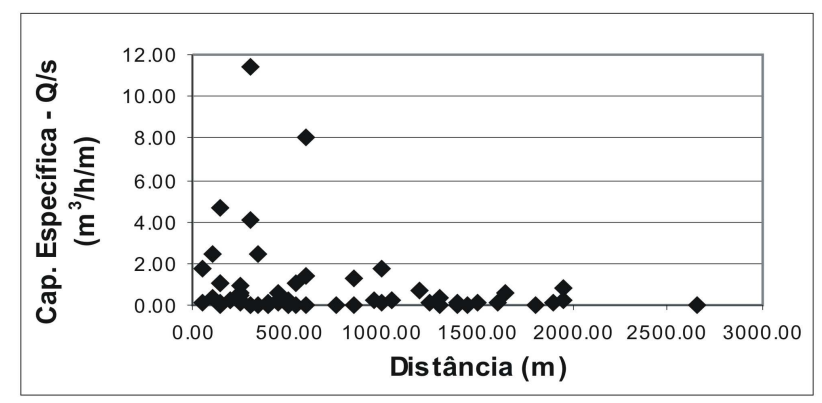

Figura 12 - Distância de intersecções de lineamentos X capacidade especifica.

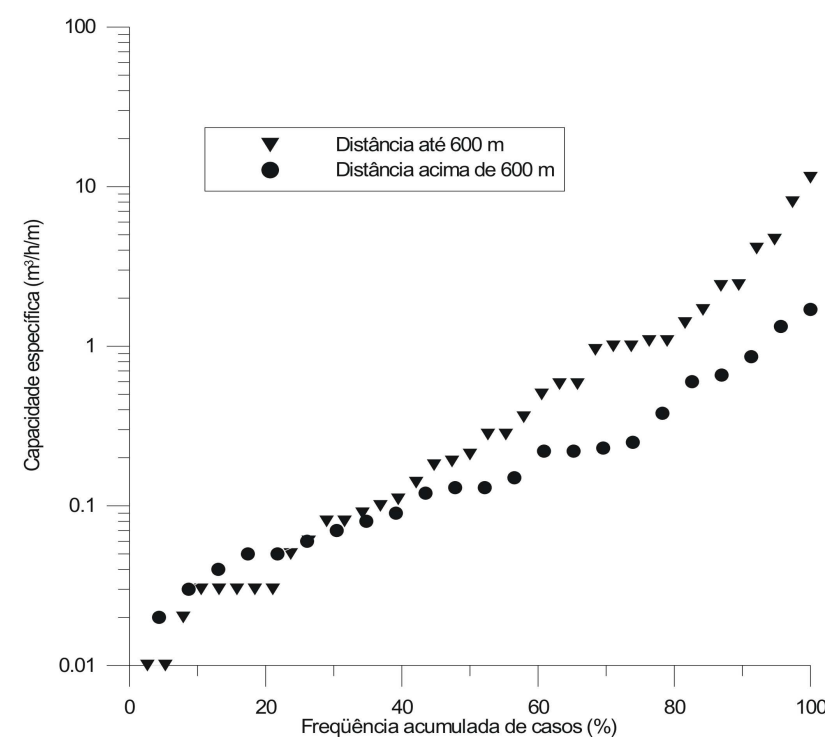

Figura 13 - Freqüência acumulada da capacidade especifica dos poços agrupados em função de sua distância da intersecção dos lineamentos.

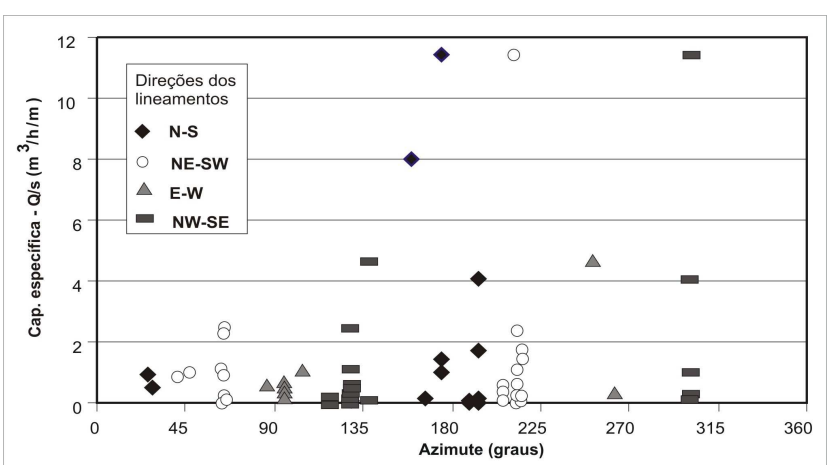

Figura 14 - Azimute dos lineamentos X capacidade específica.

mais distantes que $200 \mathrm{~m}$ dos lineamentos podem ser considerados como fora da área de sua influência, isto é, as regiões próximas aos lineamentos (até $200 \mathrm{~m}$ ) representam áreas mais fraturadas e, portanto, mais favoráveis à infiltração, circulação e armazenamento de água de subterrânea.

Considerando a produtividade dos poços em relação às inter- 
secções dos lineamentos, observou-se um padrão de até $600 \mathrm{~m}$ como área de influência. Conclui-se que as intersecções aumentam a área de influência dos lineamentos. Estima-se que isto decorre da maior largura das zonas fraturadas nas regiões de intersecção de lineamentos em relação às zonas fraturadas de um único lineamento.

As direções de lineamentos N-S, NE-SW e NW-SE são as de maior produtividade, ao passo que a direção E-W apresenta os valores mais baixos. Contudo, em todas as direções também ocorrem baixos valores, provavelmente devido à presença de fraturas fechadas, que impedem o fluxo e a acumulação de água.

Comparando o mapa morfoestrutural com a produtividade de poços nota-se que os maiores valores se relacionam com regiões intermediárias e de baixo morfoestrutural. Isso reforça a importância deste mapa no estudo hidrogeológico, já que, teoricamente, os altos morfoestruturais indicam zonas de recarga e os baixos as de acumulação, onde estruturas verticais, que delimitam basculamento dos blocos, em conexão com outras fraturas podem induzir fluxo de água subterrânea maior em direção aos baixos morfoestruturais.

As isofreqüências de zonas de juntas mostram que não há clara relação entre a densidade de juntas e a produtividade dos poços. Isso significa que não basta a ocorrência de várias fraturas e que outros fatores geológicos devem ser considerados, tais como se as fraturas estão "abertas" ou "fechadas", por exemplo, por material argiloso. Outro fator a considerar é que há poucos poços localizados nas áreas mapeadas como classes de maior densidade de zonas de juntas. Portanto, com este conjunto de dados, não é possível se avaliar com precisão a influência das classes de maior densidade (classes 9 a 12) na produtividade de poços.

A análise dos dados contribui para a construção de um modelo hidrogeológico regional da área, onde a presença de lineamentos e morfoestruturas condicionam a recarga e acumulação de água. $\mathrm{O}$ mapa morfoestrutural demonstra a importância da tectônica terciária no condicionamento hidrogeológico da região.

Devido à distribuição espacial irregular dos poços, recomendase o emprego de dados de surgências naturais para complementar o estudo em áreas sem poços. Como as fontes são ocorrências naturais, sua localização não tem influência antrópica direta, logo, podem contribuir ao melhor conhecimento do aqǘfero cristalino.

Agradecimentos À Fundação de Amparo à Pesquisa do Estado de São Paulo - FAPESP (Processo 00/05740-2) pelo apoio financeiro, ao Instituto de Geociências da Universidade de São Paulo pelo suporte técnico, ao Instituto Nacional de Pesquisas Espaciais (INPE) pela cessão das imagens de satélite, à Companhia de Pesquisa de Recursos Minerais (CPRM) pela cessão de dados aerogeofísicos e de poços. Aos revisores da RBG e aos editores deste número pelas sugestões ao texto original.

\section{Referências}

Araújo C.C. \& Macedo, A.B. 2002. Multicriteria geologic data analysis for mineral favorability mapping: application to a metal sulphide mineralized area Ribeira Valley Metallogenic Province, Brazil. Nat. Res. Research, 11:29-43.

Artur A.C. 1988. Evolução policíclica da infra-estrutura da porção sul

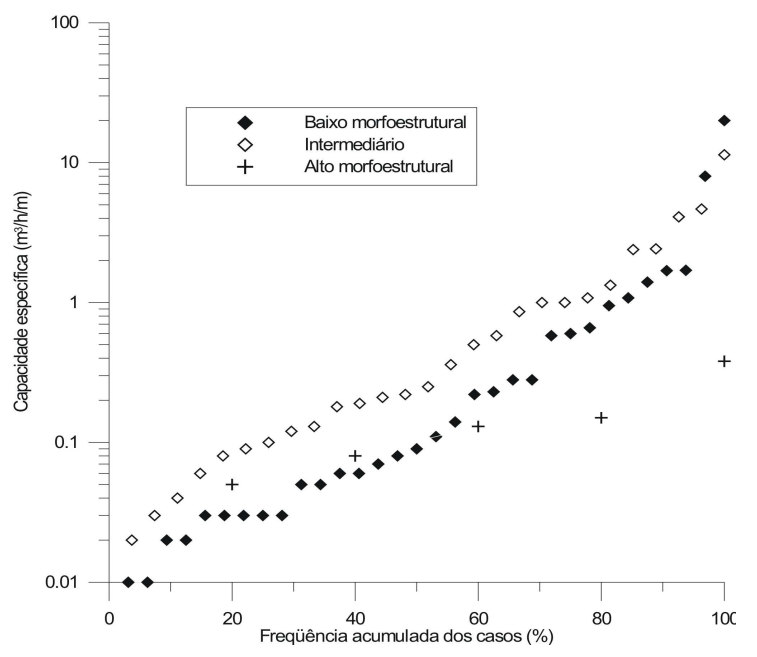

Figura 15- Freqüencia acumulada da capacidade específica dos poços agrupados em função de sua localização nas morfoestruturas.

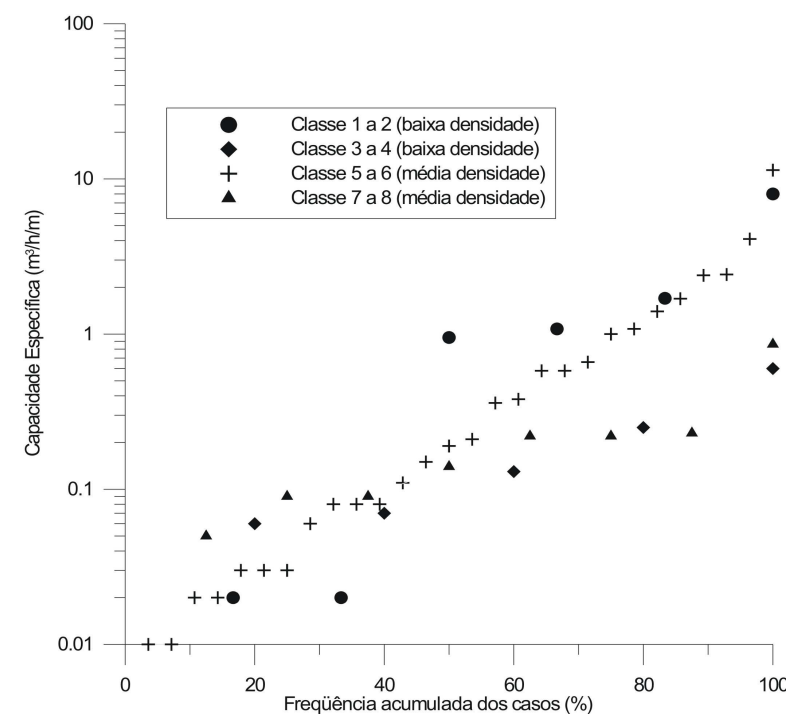

Figura 16- Freqüência acumulada da capacidade especifica dos poços agrupados em função de sua localização no mapa de contagem de zonas de juntas.

do Estado de Minas Gerais e regiões adjacentes do Estado de São Paulo. Tese de Doutorado, Instituto de Geociências, Universidade de São Paulo, 231p.

Bonham-Carter G.F. 1994. Geographic Information Systems for Geoscientists - Modelling with GIS. Ontario, Pergamon, 398p.

Campos Neto M.C, Perrota M.M., Peloggia A.U.G. 1990. A porção ocidental da Faixa Alto Rio Grande (SP-MG). In: SBG, Congr. Bras. Geol., 36, Anais, 6:2615-2630.

Chavez Jr., P. S. 1975. Atmosferic, solar and MTF corrections for ERTS digital imagery. Am. Soc. Photogrammetry, 69-79.

CPRM. 1995. Catálogo geral de produtos e serviços. Geologia: Levantamentos aerogeofísicos, 2ed, $395 \mathrm{p}$. 

do Estado de São Paulo

DAEE. 1981. Estudo de águas subterrâneas, Região Administrativa 5 Campinas. 1:343 p.

Dias R.R. \& Paradella W.R. 1997. Integração de dados aéreos gamaespectrométricos com imagens TM-Landsat no mapeamento geológico da área do Pojuca, Província Mineral de Carajás. Rev. Bras. Geof., 15:23-33.

Fernandes A.J. \& Rudolph, D.L. 2001. The influence of Cenozoic tectonics on the groundwater-production capacity of fractured zones: a case study in São Paulo, Brazil. Hydr. Journal., 9:151-167.

Fuck R.F. 2000. Interpretação de dados magnetométricos, eletromagnetométricos e gamaespectrométricos da região central da Serra dos Carajás, PA. Dissertação de Mestrado, Instituto de Geociências, Universidade de Brasília, $185 \mathrm{p}$.

GEOSOFT 1995. Geosoft mapping and processing system. Toronto, Geosoft Inc., 50p.

GEOSOFT 2001. Geosoft technical note: microlevelling using bi-directional gridding. In: www.geosoft.com/news. Consulta: abril de 2002.

Gustafsson P. 1994. Spot satellite data for exploration of fractured aquifers in a semi-arid area in southeastern Botswana. Appl. Hydrogeo., 2:9-18.

Harris J.R. 1991. Mapping of regional structure of eastern Nova Scotia using remotely sensed imagery: implications for regional tectonics and gold exploration. Can. J. Rem. Sens., 17:122-135.

Harris J.R., Bowie C., Rencz A.N., Graham D. 1994. Computer-enhancement techniques for the integration of remotely sensed, geophysical, and thematic data for the geosciences. Can. J. Rem. Sens., 20:210-221.

Harris J.R., Murray R., Hirose T. 1990. IHS transform for the integration of radar imagery and other remotely sensed data. Photogr. Eng. Rem. Sens., 56:1631-1641.

Hirata, R.C.A. \& Ferreira, L.M.R. 2001. Os aqüíferos da bacia hidrográfica do Alto Tietê: disponibilidade hídrica e vulnerabilidade à poluição. Rev. Bras. Geoc., 31:43-50.

Lowman P.D.Jr, Harris J., Masuoka P.M, Singhroy V.H, Slaney V.R. 1987. Shuttle imaging radar (SIR-B) investigations of the canadian shield: inicial report. IEEE Trans. Geosc. Rem. Sens., 25:139-159.

Mabee S.B., Hardcastle C.H., Wise D.U. 1994. A method of collecting and analyzing lineaments for regional scale fractured-bedrock aquifer studies. Ground Water, 32: 884-894.

Madrucci V. 2000. Avaliação dos produtos integrados TM-Landsat, RADARSAT e gamaespectrométricos, na caracterização tectônica e mapeamento geológico de área mineralizada em ouro na região de Alta Floresta - MT. Dissertação de Mestrado, INPE, 187p.

Madrucci V., Veneziani P., Paradella W.R. 2002. Estudo estrutural através da interpretação de imagens TM-Landsat 5 e sua associação com mineralizações auríferas em Alta Floresta, Mato Grosso. In: E.L.Klein, M.L.Vasquez, L.T. da Rosa-Costa (eds.) Contribuições à Geologia da Amazônia 3, p. 215-226.

Mattos J.T., Balieiro M.G., Soares P.C., Barcellos P.E., Meneses P.R., Csordas S.M. 1982. Análise morfoestrutural com uso de imagens MSS-Landsat e radar para pesquisa de hidrocarbonetos no estado de São Paulo. São José dos Campos, INPE, RTR/015, 167 p.

Minty B.R.S. 1991. Simple Micro-levelling for aeromagnetic data. Expl. Geophyisics, 22:591-592.

O'Leary D.W., Friedman J.D., Pohn H.A. 1976. Lineament, linear, lineation: some proposed new standards for old terms. Geol. Soc. of Am. Bul., 87:1463-1469.

Oliveira S.A.M. 1997. Uso e aplicações de sensoriamento remoto no estudo do controle hidrogeológico do aqüifero termal de Caldas Novas- GO. Dissertação de Mestrado, INPE, 111p.

Parro P.S. 1998. Magnetometria e gamaespectrometria aerotransportadas na interpretação geológico-estrutural da região dos rios Juruena e Teles Pires - MT. Dissertação de Mestrado, Instituto de Geociências, Universidade Brasília, 63 p.

Paradella W.R., Santos A.R., Dall'Agnol R., Pietsch R.W., Sant'Anna M.V. 1998. A geological investigation based on airborne (SAREX) and spaceborne (RADARSAT-1) SAR integrated products in the Central Serra dos Carajás granite area, Brazil. Can. J. Rem. Sens., 24:376-392.

Plicka M. 1974. Observations on joint zones in Moravia, Czechoslovakia. In: International Conference on the New Basement Tectonics, 1, Salt Lake City, Proceedings, 279-289p.

Rocio M.A.R. \& Veneziani P. 1993. Caracterização das condições de ocorrência das águas subterrâneas no embasamento com o emprego de técnicas de sensoriamento remoto. In: Simp. Bras. Sensoriamento Remoto, 7, Anais 3:312-314.

Riverau J.C. 1972. Notas de aula do curso de fotointerpretação. In: XI Semana de estudos - fotografia aérea e aplicações técnicas. Ouro Preto, SICEG, p. 75-121.

Rolim S.B.A. Avaliação do uso da transformação IHS na integração de dados geofisicos (aeromagnetometria) e de sensoriamento remoto (TM Landsat) para a investigação geológica na área do Pojuca (Serra dos Carajás, PA). 1993. Dissertação de Mestrado, INPE, $133 \mathrm{p}$.

Rostirolla S.P. 1997. Alguns aspectos da avaliação de favorabilidade em geologia exploratória. Rev. Bras. Geoc., 27:327-338.

Sampaio O.S. 1987. Estudo de fraturamentos como subsídio à pesquisa de água subterrânea no estado de Sergipe: uma abordagem através de dados de sensoriamento remoto. Dissertação de Mestrado, INPE, $95 \mathrm{p}$.

Sander P. 1997. Water-well sitting in hard-rock areas: identifying promising targets using a probabilistic approach. Hydrog. Journal, 5:32-43.

Sander P., Chesley M.M., Minor T.B. 1996. Groundwater assessment using remote sensing and GIS in a rural groundwater project in Ghana: lessons learned. Hydrog. Journal, 4:40-49.

Santos S.L.C. 1999. Integração digital de dados RADARSAT S-1 e aerogamaespectrométricos: contribuição ao estudo de corpos graníticos mineralizados da província estanifera de Rondônia. Dissertação de Mestrado, INPE, 162 p.

Soares P.C., Fiori A.P. 1976. Lógica e sistemática na análise e interpretação de fotografias aéreas em geologia. Not. Geomorf., 16:107-121.

Soares P.C., Luz M.E.R., Redaelli R., Guerra S.M.S. 1982. Análise morfoestrutural em fotos aéreas: aplicação na prospecção de hidrocarbonetos na bacia do Paraná. In: Simp. Bras. Sensoriamento Remoto, 2, Anais 1:157-168.

Veneziani P. 1987. Análise de movimentos da tectônica rúptil e rúptildúctil através da interpretação de produtos de sensores remotos na região do Espinhaço Meridional (MG): uma correlação com processos evolutivos. Tese de doutoramento. Instituto de Geociências, Universidade de São Paulo, 186 p.

Veneziani P., Anjos C.E. 1982. Metodologia de interpretação de dados de sensoriamento remoto e aplicações em geologia. São José dos Campos, INPE, 61p.

Waters P., Greenbaum D., Smart P.L., Osmaston H. 1990. Applications of remote sensing to groundwater hydrogeology. Rem. Sens. Rev., 4:223-264. 